\title{
NARRATIVAS DE ESTUDANTES EAD EM BLOG E APROPRIAÇÃO DE LETRAMENTOS DIGITAIS
}

\author{
Iracema Cristina Fernandes da Silva \\ (D) https://orcid.org/0000-0001-6205-781x \\ Terezinha Fernandes Martins de Souza ${ }^{2}$ \\ Dhttps://orcid.org/0000-0002-1040-424X
}

Resumo: Este artigo é um recorte da dissertação intitulada "Letramentos Digitais em Narrativas de Estudantes de Licenciatura em Pedagogia EaD" (SILVA, 2020) e tem como objetivo analisar as memórias de estudantes e narrativas em blog produzidas por estudantes desse curso pelo viés dos letramentos digitais, em uma perspectiva social e abordagem crítica. $O$ estudo foi desenvolvido com inspiração na pesquisa-formação na cibercultura (SANTOS, 2014) e na abordagem multirreferencial (BARBOSA; BARBOSA, 2008), contemplando estudo bibliográfico, estudo documental e análise de conteúdo das memórias e narrativas dos(as) estudantes. Os resultados apontam dificuldades e familiaridades no uso das tecnologias digitais pelos(as) estudantes no início do curso e, no decorrer dele, a mobilização das dimensões funcionais e comunicacionais dos letramentos digitais, bem como as dimensões da autogestão do tempo, autodireção da aprendizagem, dimensão cognitiva, comunicação on-line e social. Ao final do curso, surgiram outros usos com comunicação ubíqua, multimodalidade, fake news, games e avatares. Compreendemos que as mudanças na cultura digital são contínuas e que as apropriações cotidianas com tecnologias digitais pelos(as) estudantes potencializam os letramentos digitais existentes e auxiliam a emergência de outros, desafiando-nos, como docentes, a buscar constantes mudanças nos processos de formação.

Palavras-chave: cultura digital; tecnologias digitais; letramentos digitais; narrativas; educação a distância.

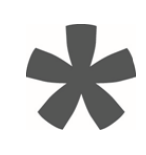

${ }^{1}$ Mestre em Educação pela Universidade Federal de Mato Grosso (UFMT). Membro do grupo de pesquisa LêTece (Laboratório de Estudos sobre Tecnologias da Informação e Comunicação na Educação). Orientadora acadêmica do Curso de Licenciatura em Pedagogia NEAD/UFMT. E-mail: cristinafernandes13@hotmail.com

2 Professora Adjunta do Instituto de Educação da Universidade Federal de Mato Grosso (UFMT). Pósdoutora em Educação pela Universidade Federal Rural do Rio de Janeiro (UFRRJ). Doutora em Educação pela Universidade Federal de Santa Catarina (UFSC) com doutoramento sanduiche pela Universidade Aberta do Brasil (UAb) Portugal. Mestre em Educação pela Universidade Federal de Mato Grosso (UFMT). Membro dos grupos de pesquisas Laboratório de Estudos sobre Tecnologias da Informação e Comunicação na Educação (LêTECE) UFMT e Docência e Cibercultura (GpDOC) UFRRJ. E-mail: terezinha.ufmt@gmail.com 


\title{
DISTANCE LEARNING STUDENTS NARRATIVES IN BLOG AND DIGITAL LITERACY APPROPRIATION
}

\begin{abstract}
This article is a piece of the dissertation entitled "Digital Literacy in Distance Learning Pedagogy Students Narratives" (SILVA, 2020) and its main goal is to analyze students' memories and narratives in blog produced by students from this course through digital literacy, in a social perspective and critical approach. The Study was developed by inspiration on the formation-research in cyberculture (SANTOS, 2014) and in the multireferential (BARBOSA; BARBOSA, 2008), contemplating bibliographical study, documental study, and Students' memories and narratives content analysis. The results show difficulties and familiarities regarding digital technologies use from student at the beginning of the course, and throughout it, the functional dimensions mobilization and digital literacy communicational, such as time self-management dimensions, apprenticeship self-direction, and cognitive dimension, social and online communication. At the end of the course, other ubiquitous communication use emerged, multimodality, fake news, games and avatars. We comprehended that the changes and in the digital culture are continuous and that day-byday approach to digital technologies by the students potentiate the existing digital literacy and help in others emergency, challenging us, as teachers, to look for constant change in formation process.
\end{abstract}

Keywords: digital culture; digital technologies; digital literacy; narratives; distance learning.

\section{NARRATIVAS DE ESTUDIANTES DE APRENDIZAJE A DISTANCIA EN BLOG Y APROPIACIÓN DE ALFABETIZACIÓN DIGITAL}

Resumen: Este artículo es parte de la disertación titulada "Alfabetización digital en narrativas de estudiantes de pedagogía a distancia" (SILVA, 2020) y su principal objetivo es analizar las memorias y narrativas de los estudiantes en el blog de los estudiantes de este curso a través de la alfabetización digital. en perspectiva social y enfoque crítico. El Estudio se desarrolló a partir de la inspiración en la formación-investigación en cibercultura (SANTOS, 2014) y en la multi referencial (BARBOSA; BARBOSA, 2008), contemplando el estudio bibliográfico, el estudio documental y el análisis de contenido de memorias y narrativas de los estudiantes. Los resultados muestran dificultades y familiaridades con respecto al uso de tecnologías digitales por parte del alumno al inicio del curso, y a lo largo del mismo, las dimensiones funcionales movilización y alfabetización digital comunicacional, tales como dimensiones de autogestión del tiempo, autodirección del aprendizaje y dimensión cognitiva, social. y comunicación en línea. Al final del curso, surgieron otros usos de comunicación ubicuos, multimodalidad, fake news, juegos y avatares. Comprendemos que los cambios y en la cultura digital son continuos y que el acercamiento día a día a las tecnologías digitales por parte de los estudiantes potencializa la alfabetización digital existente y ayuda en otras emergencias, desafiándonos a nosotros, los docentes, a buscar un cambio constante en lo proceso de formación.

Palabras clave: cultura digital; tecnologías digitales; alfabetización digital; narrativas; educación a distancia. 


\section{Introdução}

Compreender os fenômenos emergentes na cultura digital é um desafio necessário para professores(as) e pesquisadores(as) que buscam entender o desenvolvimento e a expansão do digital em rede e a sua relação com os processos educativos, pois o cotidiano das pessoas está impregnado por tecnologias digitais que têm modificado práticas e culturas diversas.

Este artigo é um recorte de uma pesquisa concluída no Mestrado realizado no Programa de Pós-graduação em Educação da Universidade Federal de Mato Grosso (UFMT), no âmbito do Grupo de Pesquisa Laboratório de Estudos sobre Tecnologias da Informação e Comunicação na Educação (LêTece). O objetivo foi compreender os usos e as apropriações dos(as) estudantes com tecnologias digitais no curso de Pedagogia modalidade Educação a Distância ( $\mathrm{EaD})$ e problematizá-los como letramentos digitais, em uma perspectiva social e abordagem crítica, pelo viés do modelo ideológico.

A pesquisa foi realizada com estudantes do curso de Licenciatura em Pedagogia EaD da UFMT, Núcleo de Educação Aberta a Distância (NEAD) - polo de Juara, situado a 695 km da capital Cuiabá.

A partir dos dados produzidos no estudo, tecemos interpretações e significações que foram organizadas em quatro partes neste artigo. Na primeira parte, apresentamos a base metodológica de abordagem qualitativa, com inspiração na pesquisa-formação multirreferencial na cibercultura. As narrativas dos(as) estudantes foram acionadas como dispositivo de pesquisa com o intuito de dar voz a estudantes que, nesta pesquisa, foram considerados(as) "praticantes culturais" conforme Certeau (1998).

Na segunda parte, dialogamos com a cultura digital, o uso das tecnologias e a emergência de ambientes on-line na EaD. Na terceira parte, discutimos os usos e as apropriações com tecnologias digitais e a mobilização de letramentos digitais na perspectiva social e abordagem crítica. Na quarta e última parte, apresentamos e discutimos as narrativas em blog e as apropriações feitas pelos(as) estudantes no desenvolvimento dos letramentos digitais. Encerramos com as considerações finais, funcionando como um espaço de discussões e reflexões acerca dos resultados, dos limites e das possibilidades do estudo. 


\section{O percurso metodológico}

Na sociedade contemporânea, investigar as redes cotidianas tecidas pelos sujeitos na cultura digital é produzir conhecimento científico e gerar oportunidade de avanços para a sociedade em vários aspectos (DEMO, 2011). Este estudo foi inspirado na pesquisa-formação na cibercultura proposta por Santos (2014), a qual tem a docência como lócus de pesquisa, espaço de formação e autoformação. $O(a)$ pesquisador(a) não é um sujeito neutro, mas sim se inclui na pesquisa de forma autocrítica e autorreflexiva. A relação entre os sujeitos e as práticas cotidianas são valorizadas, e as articulações epistemológicas e metodológicas potencializam a emergência de autorias cidadãs.

$\mathrm{Na}$ pesquisa-formação na cibercultura, segundo Santos (2014), os percursos formativos são estabelecidos pelas experiências, pelos sentimentos e por meio da linguagem; essa relação é construída pelo(a) próprio(a) pesquisador(a) e com os(as) outros(as). Sendo assim, as vivências da pesquisa se tornam experiências formativas, transformando o(a) pesquisador(a) e os(as) praticantes que dela participam. De acordo com Santos (2014), a pesquisa-formação contempla a possibilidade da mudança das práticas docentes, bem como dos sujeitos em formação. Santos (2014, p. 77) defende "que os espaços do conhecimento são múltiplos e que mobilizam saberes plurais". Nesse sentido, a pesquisa-formação também está pautada na multirreferencialidade.

A abordagem multirreferencial possibilita esta ruptura epistemológica em direção a uma aproximação do fazer educativo de forma complexa e não de maneira compartimentada, isolada do social, dos processos políticos, econômicos, históricos e culturais; há que se buscar compreender cada um dos sujeitos ou situações pesquisadas como parte de um conjunto inseparável, em que estão presentes incertezas, dúvidas, ambiguidades, mestiçagem (BARBOSA; BARBOSA, 2008, p. 247).

Na pesquisa-formação multirreferencial, os dados são qualitativos e "consistem em descrições detalhadas de situações, acontecimentos, sujeitos interações e condutas observadas; citações diretas de pessoas acerca de suas experiências, atitudes, crenças e pensamentos" (SANTOS, 2014, p. 113).

O lócus desta pesquisa foi o curso de Licenciatura em Pedagogia, modalidade a distância, do NEAD/UFMT, polo de Juara. Os(as) praticantes culturais, conforme Certeau (1988), foram os(as) estudantes do curso pesquisado, integrantes da turma 1/2017. Essa 
turma tinha 20 estudantes regularmente matriculados(as) no início do curso e, em razão de duas desistências, ficamos com 18 estudantes que compuseram a amostra da pesquisa.

A pesquisa-formação foi desenvolvida contendo estudo bibliográfico, análise documental, análise de memórias de vida e formação e análise de narrativas produzidas em blog. O objetivo foi compreender os usos e as apropriações dos(as) estudantes com tecnologias digitais no curso de Pedagogia EaD, relacionando-os aos letramentos digitais por eles(as) mobilizados.

A seguir, apresentamos as reflexões teóricas que foram tecidas no decorrer da pesquisa e que ampararam a compreensão de conceitos fundamentais para dialogar com os resultados do estudo.

\section{Cultura digital, uso de tecnologias e a emergência de ambientes on-line na educação a distância}

Os sujeitos sociais compartilham e interpretam o mundo de acordo com sua cultura, seus sentimentos e suas práticas sociais, e a interconexão mundial de computadores tem trazido mudanças para a sociedade contemporânea, as quais influenciam os seus modos de uso, as apropriações das tecnologias digitais em rede e a mudança de mentalidades. Para Santaella (2005), essas mudanças favorecem a interação de milhares de pessoas em nível político, econômico, cultural e industrial.

A estrutura social se alterou com a digitalização, que possibilitou a convergência das mídias, a interatividade e a integração das linguagens. Com o hipertexto e a hipermídia, os atos de ler, perceber, escrever, pensar e sentir adquiriram características diversas. Santaella (2005) atesta que tudo se convergiu para uma linguagem digital.

Dessa forma, sendo a linguagem precedente primordial na cultura da humanidade, a autora supracitada sugere que a cultura é dividida em eras: passamos pela cultura oral (não havia a escrita), cultura escrita (as memórias começam a ser registradas), cultura impressa (descoberta da prensa móvel de Gutenberg), cultura das massas (surge com a Revolução Industrial) e cultura das mídias (meios de comunicação ficam mais acessíveis) até chegarmos à cultura digital (cultura do acesso e da interatividade através dos meios digitais). 
[...] a cultura digital não brotou diretamente da cultura de massas, mas foi sendo semeada por processos de produção, distribuição e consumo comunicacionais a que chamo de 'cultura de mídias'. Esses processos são distintos da lógica massiva e vieram fertilizando gradativamente o terreno sociocultural para o surgimento da cultura digital ora em curso (SANTAELLA, 2003 apud SILVA, 2020, p. 22).

A cultura digital abarcou mudanças nos processos socioculturais, modificou os hábitos sociais e alterou a forma de produzir e distribuir as informações que são disseminadas instantaneamente, ou seja, as pessoas usam, consomem, apropriam-se e produzem informações na rede de forma movente e ubíqua.

Os notebooks, tablets e smartphones (celulares) nos conectam com o ciberespaço e, através da internet, temos uma revolução de informações e comunicações disponíveis a todos(as). Essa escrita on-line são interativas e dinâmicas e rompem com barreiras geográficas de espaço e tempo.

Com essas relações estabelecidas, surgem também outros modos de fazer educação, e educação on-line, que se desenvolve com a conectividade e interatividade que as interfaces dos Ambientes Virtuais de Aprendizagem (AVAs) têm possibilitado pelo uso de tecnologias digitais em rede. O on-line na EaD trouxe também a mediação, a autoria, o diálogo e a colaboração entre docentes e estudantes, e, para Santos (2002), os AVAs são espaços fecundos de significados que agregam as características da internet.

Essas mudanças significativas que emergem da cultura digital nos mostram que a universidade e as práticas de formação inicial de professores(as) passam por transformações no uso de artefatos culturais para produzir, criar e ampliar apropriações, as quais precisam ser pesquisadas, discutidas e compreendidas pelo viés dos letramentos digitais, em uma perspectiva social e abordagem crítica.

\section{Letramentos digitais: por uma compreensão da perspectiva social e abordagem crítica}

De acordo com a cultura de cada época, os seres humanos vão desenvolvendo, ampliando e modificando a linguagem. As tecnologias digitais e a internet trouxeram transformações para a sociedade, em especial nos processos de comunicação, produção e publicação das informações. 
Com isso, surgem os letramentos digitais na cultura digital mediada por tecnologias digitais. Conforme Santaella (2005), o verbal, o visual e o sonoro foram convergidos em linguagem binária (sequência de 0 e 1 ), proporcionando a universalização da linguagem e tornando possível estocar e fazer circular uma enorme quantidade de informações.

Com a expansão das tecnologias digitais, as práticas sociais de leitura e escrita passaram a ter características multifacetadas e plurais. Soares (2009, p. 20) defende que "não basta apenas ler e escrever"; é fundamental fazer o uso social de ambos em seu contexto cultural, ou seja, nas práticas cotidianas. Os letramentos têm que ser repensados na articulação entre a linguagem, as tecnologias e o processo social e histórico, que estabelecem as múltiplas formas de interação que ocorrem com a leitura e a escrita pelo meio digital.

Neste artigo, os letramentos digitais são abordados no plural por entendermos, assim como Soares (2002, p. 156), que "letramento é fenômeno plural, historicamente e contemporaneamente: diferentes letramentos ao longo do tempo, diferentes letramentos no nosso tempo". Ou seja, na cultura contemporânea, existe uma multiplicidade de letramentos que são vivenciados no cotidiano social dessa era tecnológica.

Street (2014) apresenta o letramento por uma perspectiva social e abordagem crítica. Ele atesta que temos que sair do modelo autônomo para o modelo ideológico de letramento, que reconhece que é nas práticas sociais, nas culturais e nas relações de poder que a leitura e a escrita são notoriamente estabelecidas, enquanto o modelo autônomo está pautado na divisão do letrado e iletrado e nas habilidades individuais. Os letramentos na cultura digital, segundo a concepção de Street (2014), também são práticas sociais, e assim existe uma multiplicidade deles que são vivenciados no cotidiano social.

De acordo com Rosa (2013), os letramentos digitais estão sempre em movimento, e o uso, a produção e a transformação de conteúdo em rede não podem ser pensadas em uma única dimensão, pois existem vários tipos de letramentos relacionados às tecnologias da informação e comunicação. Dessa forma, precisamos reconhecer a multiplicidade teórica, política e social dos letramentos. 
São amplas as conceituações dos letramentos digitais. Buzato (2009) também defende a ideia de diferentes letramentos digitais, praticados em contextos variados para diversas finalidades. É importante entendermos que, além de um conjunto de conhecimentos, habilidades e competências necessárias para o contexto social e tecnológico, os seres humanos também desenvolvem seus aspectos político, ético e crítico. Isso porque, segundo Xavier (2005), os letramentos estão situados em um contexto social, político, econômico e cultural, e as relações de poder que são estabelecidas no decorrer do tempo e da história produzem os conhecimentos na sociedade contemporânea, em que o digital em rede é predominante.

A perspectiva social e abordagem crítica dos letramentos em Street (2014) nos mostram que eles não são fixos, e sim são práticas sociais situadas no processo de convergência das mídias que tem transformado a circulação de linguagens através da mediação digital. Souza, Silva e Cruz (2013, p. 13) citam Buzato (2009) e destacam os três atributos dos quais os letramentos são constituídos:

Figura 1 - Atributos dos letramentos digitais

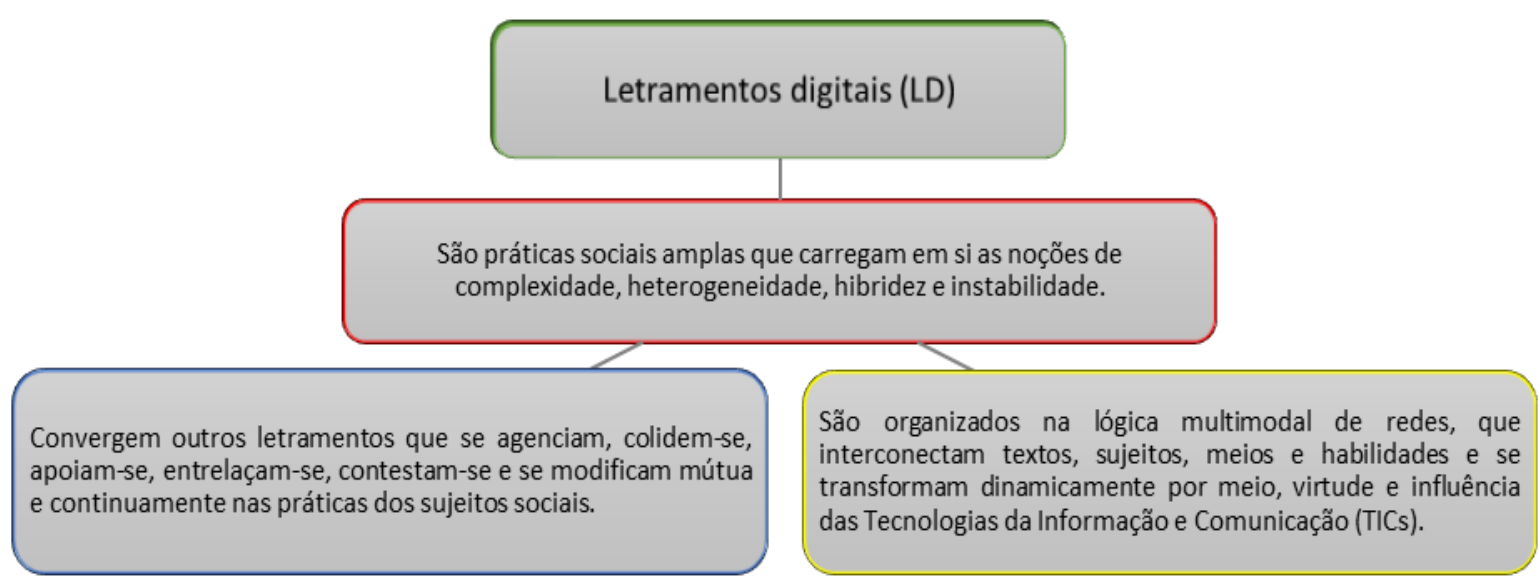

Fonte: Baseado em Souza, Silva e Cruz (2013, p. 13).

Esses atributos nos levam a compreender que os letramentos digitais em rede são múltiplos e estão sempre em movimento no uso, sendo construídos e transformados no contexto sócio-histórico e cultural em que estamos inseridos(as).

Nesse sentido, o tópico a seguir apresenta os letramentos digitais apropriados pelos(as) estudantes em práticas sociais vivenciadas no contexto do curso de Licenciatura em Pedagogia EaD. 


\section{Narrativas em blog: apropriações pelos(as) estudantes e desenvolvimento de letramentos digitais}

A disciplina "Estudos para Introdução à EaD - Educação Aberta e a Distância", primeira disciplina cursada pelos(as) acadêmicos(as) no curso de Licenciatura em Pedagogia EaD do NEAD/UFMT, teve como objetivo levar os(as) estudantes a refletirem sobre o sentido de ser estudante em um curso na modalidade a distância e a organizarem, de forma proativa, a caminhada de estudos.

Desse módulo resultou um Seminário Integrador denominado "Memórias de Estudante". As Memórias de Estudante constituíram-se de uma produção narrativa, com características de narrativas de si, em que os(as) autores(as) contavam seus percursos de vida e formação. Essas narrativas foram socializadas no AVA do curso e apresentadas no seminário citado. Nesse componente curricular, os(as) estudantes tiveram a oportunidade de fazer uma retrospectiva histórica de sua vida escolar até seu ingresso na universidade, na modalidade $\mathrm{EaD}$, incluindo as expectativas com relação à formação no curso.

No quadro a seguir, apresentamos fragmentos das 18 narrativas das Memórias de Estudante analisadas. Destas, nove relatam experiências com o uso de tecnologias, sejam analógicas, sejam digitais, e possíveis relações com o seu ingresso no curso de graduação.

Quadro 1 - Temas das Memórias de Estudante relacionados a tecnologias analógicas e digitais

\begin{tabular}{|l|l|}
\hline \multicolumn{1}{|c|}{ Tema } & \multicolumn{1}{c|}{ Experiências com uso de tecnologias } \\
\hline $\begin{array}{l}\text { Tecnologias } \\
\text { analógicas }\end{array}$ & $\begin{array}{l}\text { "Outra recordação boa é o cheirinho de álcool nas provas ou desenhos para } \\
\text { colorir impressos [no mimeógrafo] que eram dados." (A. M. R. P.) }\end{array}$ \\
\hline \multirow{5}{*}{$\begin{array}{l}\text { Tecnologias } \\
\text { digitais }\end{array}$} & $\begin{array}{l}\text { "Um trabalho escolar que eu tinha me esforçado tanto pra fazer nas minhas } \\
\text { intimidade alguma com a tecnologia coisa que para os outros era fácil, mas } \\
\text { me esforcei e fiz, e ainda paguei hora na lan house e também paguei para } \\
\text { imprimir do pouco dinheiro que as vezes me sobrava) rasgou e jogou no lixo } \\
\text { na minha frente sem ao menos folheá-lo e ainda disse que aquele era } \\
\text { trabalho típico de menininha vagabunda do Jardim América, mal sabia } \\
\text { minhas origens para me julgar daquela forma [...]" (R. O.) } \\
\text { "Ouando recebi uma mensagem em meu celular, de uma colega, dizendo que } \\
\text { eu tinha sido aprovada no vestibular. [...] a imagem que ela havia mandado, } \\
\text { onde encontrava-se meu nome de aprovada." (S. F. C.) } \\
\text { "Assim que abriu no site, o link para preencher o formulário, fiquei irritada e } \\
\text { confusa, pois, quando tentava acessar, aparecia uma mensagem dizendo }\end{array}$ \\
\hline
\end{tabular}




\begin{tabular}{|c|c|}
\hline & $\begin{array}{l}\text { que eu não constava na lista de aprovados, assim que digitava meu CPF." (V. } \\
\text { N.) }\end{array}$ \\
\hline Tecnologias & $\begin{array}{l}\text { "Não se usava a tecnologia naquele tempo, era muito distante da nossa } \\
\text { realidade, só sabia que existia porque a secretaria utilizava." (V. N.) }\end{array}$ \\
\hline $\begin{array}{l}\text { Tecnologia, } \\
\text { plataforma }\end{array}$ & $\begin{array}{l}\text { "Em relação aos fatos da época não tinha a tecnologia e o desenvolvimento } \\
\text { social econômico e cultural que temos hoje." (M. A. S. B.) } \\
\text { "Estou encontrando muitos obstáculos, foi difícil entrar na plataforma, mas } \\
\text { cada dia que passa sinto vontade de aprender e concluir o curso." (M. A. S. } \\
\text { B.) }\end{array}$ \\
\hline $\begin{array}{l}\text { Tecnologia, } \\
\text { plataforma } \\
\text { virtual, EaD }\end{array}$ & $\begin{array}{l}\text { "Em relação ao curso devido ser a distância é muita tecnologia que vamos ter } \\
\text { que usar, e isso é meio complicado pra mim que não tenho muito prática, } \\
\text { mas venho notando que não é somente a distância pois estamos em contato } \\
\text { constante com a plataforma virtual e a orientadora, isso é bom devido as } \\
\text { dúvidas que vamos tendo logo já nos são explicadas e nos auxiliam de forma } \\
\text { que nem percebemos que realmente é um curso a distância." (A. M. R. P.) } \\
\text { "Para mim está sendo novidade estudar a distância, essa tecnologia que a } \\
\text { plataforma nos mostra é fantástico, sair dos livros e entrar em um universo } \\
\text { totalmente digital é magnifico. Logo eu que era tão leiga sobre a tecnologia, } \\
\text { estar estudando assim está sendo diferente. A cada dia me descubro e me } \\
\text { encanto nesse mundo Pedagógico que abrange tantas áreas." (K.C.C.V.) }\end{array}$ \\
\hline $\begin{array}{l}\text { EaD, } \\
\text { plataforma }\end{array}$ & $\begin{array}{l}\text { "Estou tendo dificuldades com a psicologia, muitas teorias, também pelo } \\
\text { fato do curso ser à distância e por não dominar a Plataforma." (C. F. M.) }\end{array}$ \\
\hline $\begin{array}{l}\text { Tecnologias } \\
\text { digitais, } \\
\text { dispositivos } \\
\text { móveis }\end{array}$ & $\begin{array}{l}\text { "Na época não existia tanta tecnologia como hoje, mais ganhar um celular } \\
\text { 'tijolão' nessa época, era como ganhar na loteria." (V. M. S. P.) } \\
\text { "Hoje, as pessoas só sabem ficar no celular, tablete, computador, famílias e } \\
\text { amigos sem conversa, silenciosos, sem uma pegadinha na mão, um beijo no } \\
\text { cantinho da boca, hoje só se comunicam através de WhatsApp, nós } \\
\text { realmente tivemos infância." (V. M. S.P.) }\end{array}$ \\
\hline Inter & $\begin{array}{l}\text { "A evolução da tecnologia, antigamente formávamos grupos de estudos } \\
\text { iamos para biblioteca através dos livros e leituras fazíamos os trabalhos, hoje } \\
\text { em dia com a tecnologia avançada geralmente já realizam pesquisas pela } \\
\text { internet." (A. M. R. P.) } \\
\text { "Faltando uma semana para fazer o vestibular eu falei para minha irmã que } \\
\text { é pedagoga que eu ia presta o vestibular de pedagogia da UAB e ela disse: } \\
\text { você já estudou? Eu disse não, ela ficou louca, vamos estudar agora já pegou } \\
\text { meu notebook começou a me passar atualidades me deu umas dicas de } \\
\text { redação para eu treinar e disse para ver muito noticiários que poderia cair } \\
\text { coisas recentes como a lava-jato, superlotação de cadeias etc." (E. C. S.) }\end{array}$ \\
\hline Redes & $\begin{array}{l}\text { "Um certo dia minha irmã mais velha que mora em Juína ela é contabilista } \\
\text { me marcou em um link do facebook onde falava da faculdade a distância } \\
\text { para entrar no site e ver, mas não dei muita importância, [...] passou se mais } \\
\text { ou menos uma semana estava na catequese e] uma amiga da igreja me falou } \\
\text { da faculdade a distância pela UAB e disse que tinha visto no face mas nem } \\
\text { dei muita moral também e ela começou a insistir, [...] vamos, vamos fazer se } \\
\text { passar nós vamos estudar juntas] vamos e ela foi falando um monte de coisa } \\
\text { e eu fui gostando, disse a ela que ia conversar com mev esposo e no outro dia } \\
\text { eu dava a resposta." (E. C. S.) } \\
\text { "Já estava tarde umas onze horas da noite, quando minha amiga do jogo me } \\
\text { mandou uma mensagem no whatsapp me dando os parabéns [...] você } \\
\text { passou no vestibular." (E. C. S.) }\end{array}$ \\
\hline Organização & "E eu não parava de pensar desde então como vou conseguir conciliar os \\
\hline
\end{tabular}




\begin{tabular}{|l|l|}
\hline espaço/tempo & $\begin{array}{l}\text { estudos, com a família, com o serviço doméstico, minha catequese pois sou } \\
\text { catequista também, enfim com o meu dia-a-dia e também já comecei a me } \\
\text { programar e me organizando e priorizando o horário que ia ficar para meus } \\
\text { estudos diário." (E.C. S.) }\end{array}$
\end{tabular}

Fonte: Silva (2020).

Elaborado a partir das Memórias de Estudante 2018.

Essas narrativas demonstram os percursos tecnológicos dos quais os(as) praticantes culturais fizeram uso: mimeógrafo, computadores, lan house, celulares, notebooks, Facebook e WhatsApp até chegarem ao AVA do curso, em que realizam seus estudos.

As dificuldades em lidar com tais artefatos foram destacadas por muitos(as) estudantes, que mencionaram um uso funcional, do que se subentende o domínio da primeira dimensão dos letramentos digitais, em que são desenvolvidas habilidades técnico-operacionais. Essa seria a fase da inclusão digital, que envolve o acesso e manuseio de dispositivos e plataformas (SOUZA, 2016).

A partir dessas análises, a intenção foi dar continuidade às narrativas para que os(as) praticantes culturais expressassem, via AVA, as experiências com o uso de tecnologias.

Com o vídeo "As Invenções Digitais de Si", de autoria de Tania Lucía Maddalena, que apresenta recortes da tese de doutorado "Digital Storytelling: uma experiência de pesquisa-formação na cibercultura" (MADDALENA, 2018), estabelecemos uma reflexão com o cotidiano de formação, visando potencializar o desejo dos(as) estudantes em registrar as experiências de aprendizagem com o uso de tecnologias digitais no curso.

Então, para dar continuidade às narrativas, optamos pelo uso do blog do AVA, que disponibiliza uma gama de interfaces que potencializam o trabalho pedagógico com o digital em rede e que, até aquele momento, não havíamos utilizado no curso. As narrativas foram entendidas na perspectiva de Benjamin (2012) como dispositivos de produção de dados e foram utilizadas buscando o seu lugar inspirador, artesanal e reflexivo, pois a ressignificação da própria história é uma maneira de transformá-la.

A seguir, apresentamos os cinco temas/roteiros que emergiram das temáticas vindas das Memórias de Estudante. 
Quadro 2 - Temas das Memórias de Estudante

1. Tecnologias digitais já conhecidas antes do curso de Licenciatura em Pedagogia EaD e de que fez uso no AVA; novas apropriações de tecnologias digitais usando o AVA durante o curso; interfaces do AVA usadas para a aprendizagem.

2. Modos de encontrar as informações na internet; páginas que acessa; apreciação dos textos, imagens e demais informações encontradas; checagem da veracidade das informações antes de compartilhar; normas de publicação, divulgação e reprodução de conteúdo online; produção, reprodução ou alteração de conteúdo ou imagem da internet para compartilhamento.

3. Uso de interfaces do AVA para se comunicar com colegas, orientadora e professores(as) formadores(as); outras formas de se comunicar no curso para além do AVA, como grupo de WhatsApp, Facebook ou outra rede social; aspectos interessantes do uso desses meios para produzir algo novo no curso.

4. A formação inicial para uso de tecnologia digital oferecida pelo curso e apropriações para usar o AVA; o que já conhecia das interfaces do AVA (envio de arquivo, fórum, biblioteca on-line, questionário on-line, chat, blog, wiki etc.); quais entre as interfaces do AVA considera terem sido uma nova apropriação; se não fosse naquele formato, como estruturaria uma formação para suprir as necessidades de uso de tecnologias digitais e interfaces para utilização do AVA.

5. Itinerários cotidianos com uso de tecnologias digitais em práticas sociais (livre).

Fonte: Elaborado com base nas temáticas vindas das Memórias de Estudante (SILVA, 2020).

Souza (2016) menciona que as contextualizações das práticas de letramentos digitais ocorrem nas relações social, política, econômica e cultural, em que os(as) participantes interpretam e atribuem sentido aos fatos e às experiências vividas. Foram analisadas 18 narrativas em blog; neste artigo, apresentamos alguns fragmentos.

Figura 2 - Fragmentos das narrativas em blog

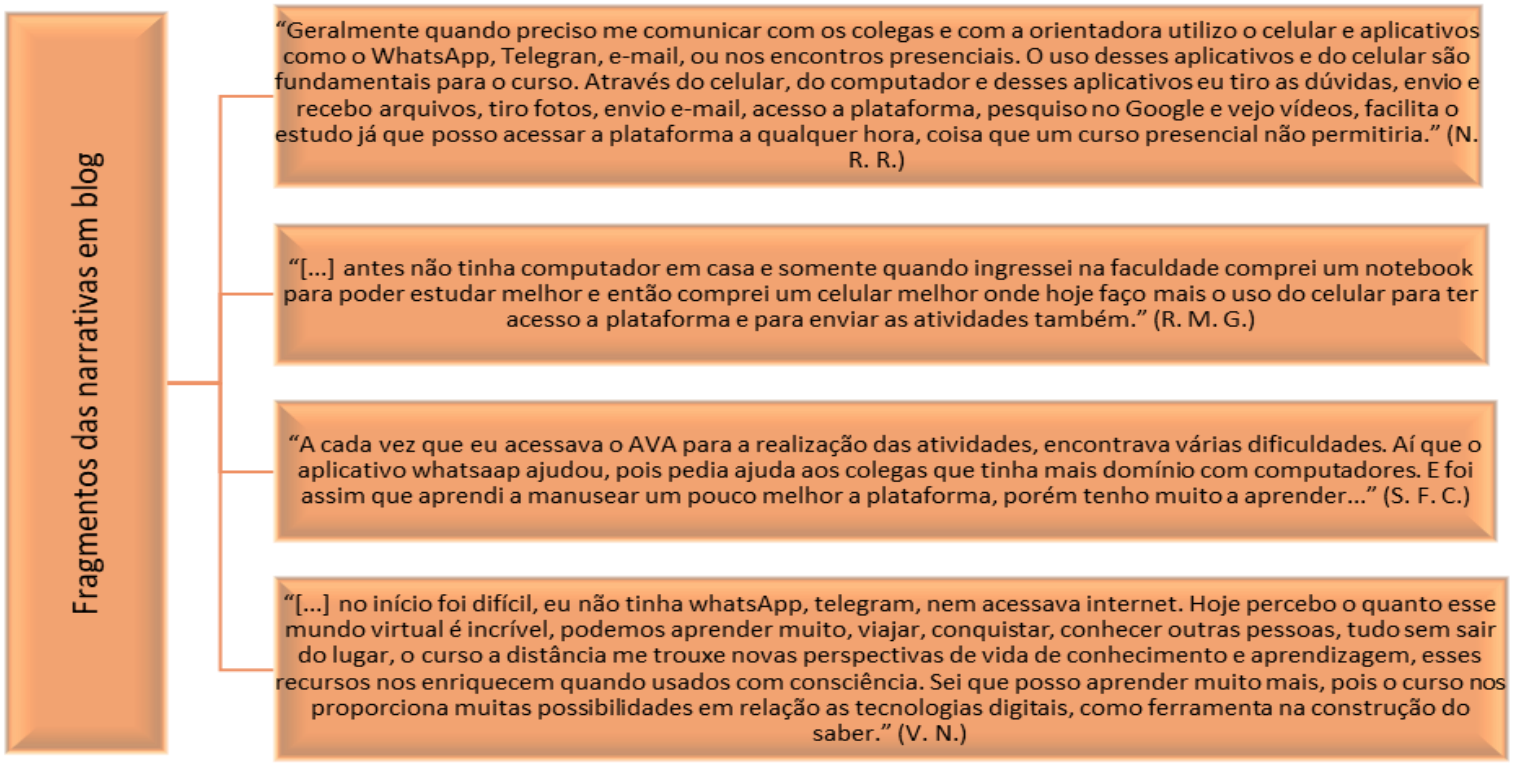

Fonte: Elaborado com base nas narrativas do blog (SILVA, 2020). 
Percebemos, nas falas dos(as) estudantes, que o acesso a computador, notebook, celular e internet era limitado e que, após o ingresso no curso, que trabalha com plataforma virtual, eles(as) sentiram a necessidade de buscar gradativamente a aquisição desses artefatos culturais que viabilizaram o acesso aos bens culturais. Mas, destacando o pensamento de Jenkins (2009), aparelhos sofisticados não garantem a convergência de mídias, que congrega três fenômenos: o uso complementar de diferentes mídias, a produção cultural participativa e a inteligência coletiva. Essa convergência é interna e ocorre na interação entre pessoas mediada por mídias digitais; quando isso é internalizado no sujeito, ele se apropria e é capaz de gerar transformações culturais e sociais.

Além do uso do AVA no curso, os(as) praticantes culturais citaram a integração de outras mídias e interfaces digitais, como e-mail, WhatsApp e Telegram, que funcionaram como dispositivos mediadores no processo de ensino e aprendizagem. Mencionaram também "acesso a sites", "fazer pesquisas" e utilização dos celulares conectados à internet para uso dos aplicativos das redes sociais.

Constatamos, assim como Lemos e Lévy (2010), que os processos de produção, criação, comunicação e circulação de bens e serviços são alterados através das tecnologias de informação e comunicação. E Dudeney, Hockly e Pegrum (2016) nos falam que o uso progressivo de múltiplas mídias envolve habilidades linguísticas, multimidiáticas, espaciais, cinestésicas, entre outras.

Do ponto de vista dos letramentos digitais, identificamos o letramento funcional, o comunicacional, o informacional e o social nas narrativas dos(as) praticantes culturais, mesmo antes do ingresso no curso. O letramento digital funcional ocorre quando a pessoa domina as habilidades básicas ou técnico-operacionais, como ligar um computador, digitar, criar pastas e salvar arquivos. O letramento digital comunicacional refere-se às habilidades de comunicação on-line via celulares e AVAs. O letramento digital informacional é a capacidade de manusear, integrar e avaliar informações, transformando-as em conteúdos úteis. O letramento digital social é a interação em ambientes virtuais, com habilidades de escolha, análise e atitudes éticas, reconhecendo as consequências e vantagens do uso das mídias digitais (SOUZA, 2016). 
A comunicação ubíqua foi identificada nesse fragmento da narrativa de N. R. R.: "essas tecnologias ajudam muito no curso de Pedagogia, quando precisamos acessar a plataforma [...] fazemos de onde estamos e a qualquer momento" (SILVA, 2020, p. 69). Podemos destacar também o rompimento da noção de espaço e tempo que é característica da modalidade $\mathrm{EaD}$ e a mobilidade que os dispositivos móveis ligados à internet disponibilizam aos seus usuários e às suas usuárias. Segundo Santaella (2013), os dispositivos móveis (celulares) podem ser considerados ubíquos a partir do momento em que podem ser levados e usados em qualquer lugar, possibilitando condições de leitura, de escrita e de acesso ao conhecimento e às informações, fazendo surgir então o leitor ubíquo.

As apropriações de tecnologias digitais são culturais, e, na cultura digital, o AVA tem demonstrado grande potencial como espaço de aprendizagem e de troca de informações, proporcionando mudanças socioculturais e formativas. No quadro a seguir, apresentamos reflexões pertinentes das narrativas em blog dos(as) estudantes.

Quadro 3 - Apropriações destacadas nas narrativas em blog

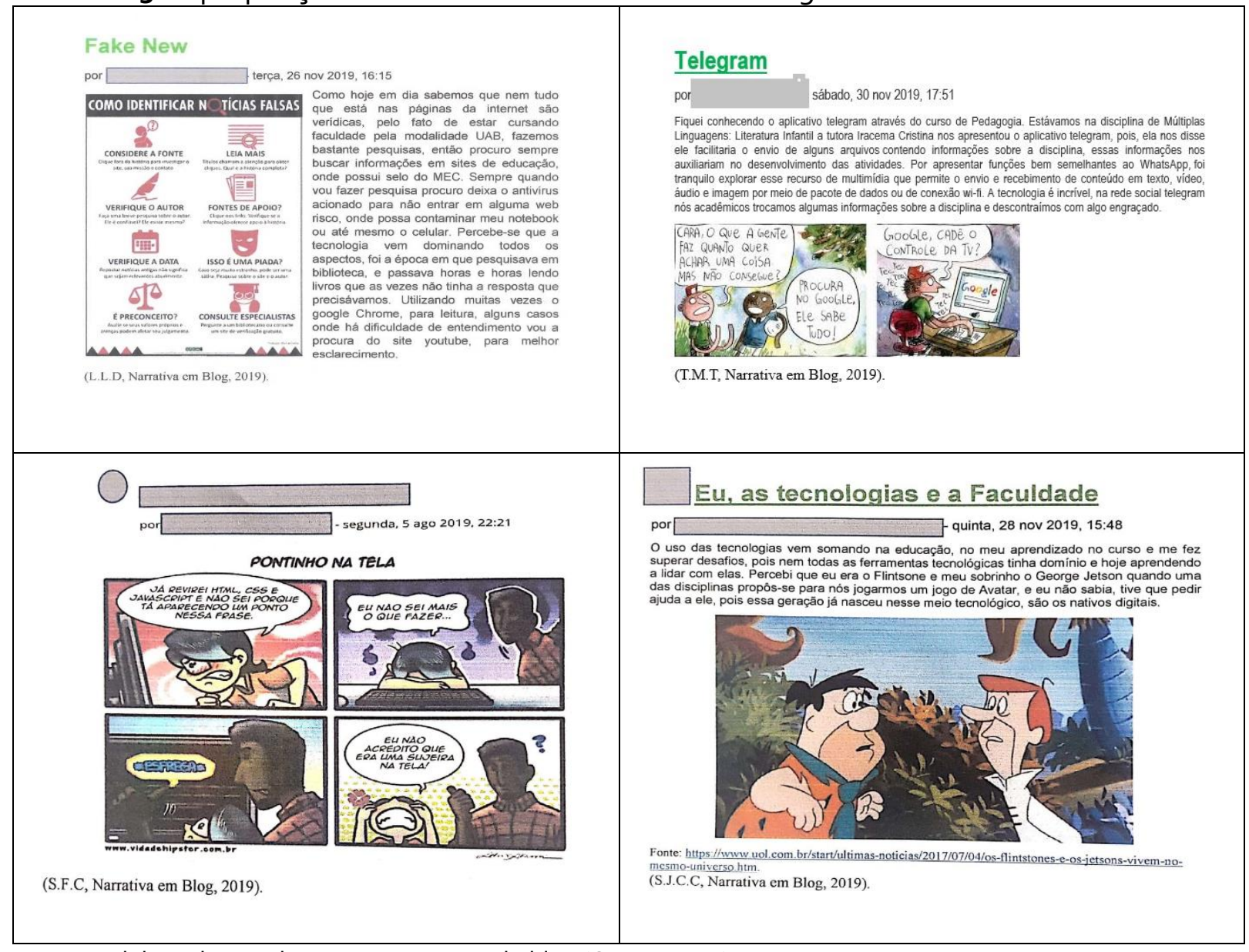

Fonte: Elaborado com base nas narrativas do blog (SILVA, 2020). 
O quadro 3 demonstra que houve apropriações de outros letramentos digitais por parte dos(as) estudantes. Destacamos aqui: fake news, Google, linguagem multimodal e games.

A plasticidade e a fluidez da interface digital possibilitam a grande circulação de informações e a difusão feita por diferentes mídias sociais. É também campo fértil para que ocorra a polarização das fake news, tipo de comunicação em rede que traz imbricados jogos de interesses que são identificados por sujeitos possuidores de habilidades de letramentos digitais, os quais são essenciais na atual cultura contemporânea, que é a cultura digital.

O Google aparece como a interface de busca mais abrangente da internet. A prática de pesquisa digital tem mudado diversos aspectos da vida humana, e essa plataforma nos remete à websemântica resultante da terceira onda da internet. O acesso à informação, que antes só era possível no formato físico, passa para o formato digital, e agora temos grande volume de sites, repositórios e bibliotecas virtuais com muitos acervos que podem ser acessados rapidamente.

A imagem apresentada na narrativa da praticante cultural S. F. C. mostra que o personagem da história em quadrinhos já possui conhecimentos específicos de informática, como HTML, CSS e JavaScript, porém não consegue resolver algo básico; ou seja, do simples ao complexo, os letramentos digitais são desenvolvidos no uso social cotidiano. A estudante apresentou a linguagem multimodal, que vai além da verbal escrita; ela utiliza múltiplas formas para expressar a mensagem e suas aprendizagens com tecnologias digitais. Para Santaella (2005), no meio digital, é possível criar e recriar a mensagem de forma mais criativa. Isso é uma marca da cultura digital, em que ocorre a hibridização de linguagens: o verbal, o visual e o sonoro vão se desdobrando em diversas formas de linguagens (SILVA, 2020, p. 75).

O uso dos jogos é destacado pela praticante cultural S. J. C. C. quando o curso, através de uma das disciplinas, possibilitou essa experiência através de games com avatar. Por meio dos avatares, tem-se um corpo digital virtual da pessoa que joga e que, dentro de um ambiente virtual, interage com os demais sujeitos ali representados. As potencialidades dos jogos e games eletrônicos para uso educacional são defendidas por autores como Santaella (2013) e Müller e Cruz (2015) por serem acessíveis em múltiplas 
plataformas e por engajarem os(as) estudantes em conceitos científicos através da aprendizagem experimental imersiva.

As tecnologias digitais citadas, em uso no curso e nas práticas sociais, promoveram conhecimentos, habilidades e aprendizagens em processos formativos. Conforme atesta Souza (2016), podemos dizer que as dimensões dos letramentos digitais (social, linguística, funcional, pedagógica, informacional, comunicacional, comunicação on-line, autogestão, autodireção e cognitiva) foram mobilizadas pelos(as) praticantes culturais em suas narrativas.

Com as apropriações observadas nas narrativas dos(as) praticantes culturais, queremos destacar o papel da universidade na formação inicial de professores(as) com tecnologias que potencializem os letramentos digitais com uma perspectiva social e abordagem crítica (STREET, 2014) para além das habilidades e competências individuais. Assim, eles(as) lançam mão de um olhar mais crítico, com engajamento social, político e cultural, para o fortalecimento identitário, para o empoderamento e para atuarem de forma crítica e autônoma na cultura digital, transformando o seu contexto social.

\section{Conclusão}

Em busca de reflexões pelo vasto campo da cultura digital, das tecnologias e dos letramentos digitais, esta pesquisa foi realizada nas e com as práticas cotidianas de formação no curso de Licenciatura em Pedagogia EaD do NEAD/UFMT. Teve-se em vista que, para atuar com autonomia e criticidade na sociedade contemporânea, é imprescindível que os(as) estudantes sejam letrados(as) digitalmente para assim produzirem mudanças e transformações que envolvam estruturas de poder, lutas de classe, entre outras coisas vivenciadas cotidianamente.

Os letramentos digitais circulam em diferentes esferas da sociedade, são complexos e são amplos. Um letramento complementa o outro, tornando-se uma rede diversificada e heterogênea com muitas dimensões e significados. Quando concebidos para além de habilidades, competências ou capacidades individuais, os letramentos digitais levam os sujeitos a estabelecerem relações, a exercerem a reflexão e a ter criticidade diante das informações que circulam em rede.

Ao estabelecer essas relações nas práticas sociais letradas, o discurso, o poder e as identidades ganham sentido, assim como defende o modelo ideológico na perspectiva 
social e abordagem crítica dos letramentos. Podemos dizer que as experiências com o uso de tecnologias digitais na vida cotidiana e nos processos formativos da universidade mobilizaram mudanças nos modos de ler, escrever, produzir e compartilhar conhecimentos, expandindo os letramentos digitais dos(as) estudantes.

Nos fragmentos das Memórias de Estudante, identificamos as seguintes dimensões dos letramentos digitais: funcional, informacional, comunicacional, autogestão do tempo e social. Nas narrativas em blog, os(as) praticantes culturais destacaram, além dos letramentos já citados, outros conhecimentos que foram sendo apropriados no decorrer do percurso da formação acadêmica - o que nos leva a reconhecer as potencialidades e possibilidades da $\mathrm{EaD}$ na cultura digital com o uso do AVA em processos formativos, processos esses que rompem com um paradigma tradicional de educação, atuando pelos princípios da educação on-line.

As práticas mediadas pelas tecnologias digitais com a utilização do AVA levaram os(as) estudantes ao uso de outras mídias e interfaces, que potencializaram a mobilização de outros letramentos da cultura digital, como os games e seus avatares, a comunicação ubíqua, as linguagens multimodais e as fakes news. Assim, a convergência de tecnologias e mídias no AVA (e para além dele) mobilizou, nas práticas formativas, a ampliação das dimensões linguística e social dos letramentos digitais, que são sistemas abertos e foram expandidos por meio da interação, mediação e participação colaborativa.

A imersão na pesquisa-formação com um olhar multirreferencial nos possibilitou entender que o processo de formação é complexo, amplo e múltiplo. Não se separa formação de cultura e estas das experiências vivenciadas pelos(as) praticantes culturais no processo. As reflexões teóricas e conceituais realizadas durante a pesquisa nos mostraram que a comunicação na cultura digital é fluida, que as mudanças são constantes e contínuas e que, portanto, estudos sobre tais questões carecem de continuidade.

Diante da instabilidade social, cultural e política, é essencial pensar nos processos formativos dos(as) praticantes culturais enquanto futuros(as) pedagogos(as) que atuarão em uma sociedade tecnologicamente letrada, instigando-os(as) a ter um olhar reflexivo sobre suas práticas, sobre o processo de ensino e aprendizagem, sobre o currículo e 
sobre sua própria formação. Enfim, os desafios devem ser vencidos pela busca constante das possibilidades futuras de desenvolvimento de aprendizagens e de pesquisas que atendam as demandas educacionais necessárias ao século XXI.

\section{Referências}

BARBOSA, Silvia Maria Costa; BARBOSA, Joaquim Gonçalves. Etnometodologia multirreferencial: contribuições teórico-epistemológicas para a formação do professorpesquisador. Revista Educação e Linguagem, São Paulo, ano 11, n. 18, p. 238-256, 2008.

BENJAMIN, Walter. Magia e técnica, arte e política: ensaios sobre literatura e história da cultura. São Paulo: Brasiliense, 2012. v. 1.

BUZATO, Marcelo El Khouri. Letramento e inclusão: do estado-nação à era das TIC. Delta: Documentação de Estudos em Linguística Teórica e Aplicada, São Paulo, v. 25, n. 1, p. 1-38, 2009. Disponível em: http://dx.doi.org/10.1590/S0102-44502009000100001. Acesso em: 1 jun. 2021.

CERTEAU, Michel de. A invenção do cotidiano: artes de fazer. 3. ed. Petrópolis: Editora Vozes, 1998.

DEMO, Pedro. Praticar ciência: metodologias de conhecimento científico. São Paulo: Saraiva, 2011.

DUDENEY, Gavin; HOCKLY, Nicky; PEGRUM, Mark. Letramentos digitais. Tradução de Marcos Marcionilo. São Paulo: Parábola Editorial, 2016.

JENKINS, Henry. Cultura da convergência. São Paulo: Aleph, 2009.

LEMOS, André; LÉVY, Pierre. O futuro da internet: em direção a uma ciberdemocracia planetária. São Paulo: Paulus, 2010.

MADDALENA, Tania Lucía. Digital storytelling: uma experiência de pesquisa-formação na cibercultura. 2018. Tese (Doutorado em Educação) - Centro de Educação e Humanidades, Universidade do Estado do Rio de Janeiro, Rio de Janeiro, 2018.

MÜLLER, Ana Cristina Nunes Gomes; CRUZ, Dulce Márcia. Uso de jogos eletrônicos na escola e eventos de letramento: uma proposta de oficinas para docentes do Ensino Fundamental. In: SEMINÁRIO JOGOS ELETRÔNICOS, EDUCAÇÃO E COMUNICAÇÃO, 11., 2015, Salvador. Anais [...]. Salvador: UNEB, 2015, p. 145-152.

ROSA, Fernanda Ribeiro. Por um indicador de letramento digital: uma abordagem sobre competências e habilidades em TICs. In: CONGRESSO CONSAD DE GESTÃO PÚBLICA, 6., 2013, Brasília. Anais [...]. Brasília: CONSAD, 2013. https://letramento-digital-eeducacao8.webnode.com/_files/200000034dabo6dca49/Por\%20um\%2oindicador\%20dig ital.pdf. Acesso em: 30 marc. 2021. 
SANTAELLA, Lúcia. Comunicação ubíqua: repercussões na cultura e na educação. São Paulo: Paulus, 2013.

SANTAELLA, Lúcia. Cultura e artes do pós-humano: da cultura das mídias à cibercultura. São Paulo: Paulus, 2003.

SANTAELLA, Lúcia. Matrizes da linguagem e pensamento: sonora, visual e verbal. 3. ed. São Paulo: lluminuras: FAPESP, 2005.

SANTOS, Edméa Oliveira dos. Ambientes virtuais de aprendizagem: por autorias livres, plurais e gratuitas. Revista da FAEEBA: educação e contemporaneidade, Salvador, v. 11, n. 18, p. 417-424, jul./dez. 2002.

SANTOS, Edméa Oliveira dos. Pesquisa-formação na cibercultura. Santo Tirso: Whitebooks, 2014 .

SILVA, Iracema Cristina Fernandes da. Letramentos digitais em narrativas de estudantes de Licenciatura em Pedagogia EaD. 2020. Dissertação (Mestrado em Educação) - Instituto de Educação, Universidade Federal de Mato Grosso, Cuiabá, 2020.

SOARES, Magda. Letramento: um tema em três gêneros. 3. ed. Belo Horizonte: Autêntica Editora, 2009.

SOARES, Magda. Novas práticas de leitura e escrita: letramento na cibercultura. Educação e Sociedade, Campinas, v. 23, n. 81, p. 143-160, dez. 2002. Disponível em: https://www.scielo.br/j/es/a/zG4cBvLkSZfcZnXfZGLzsXb/abstract/?lang=pt. Acesso em: 6 jul. 2019.

SOUZA, Terezinha Fernandes Martins de. Ondas em ressonância: letramentos digitais de estudantes na Universidade Aberta de Portugal. 2016. Tese (Doutorado em Educação) Centro de Educação, Universidade Federal de Santa Catarina, Florianópolis, 2016.

SOUZA, Terezinha Fernandes Martins de; AMANTE, Lucia; CRUZ, Dulce Márcia. Formação de professores na perspectiva dos letramentos/literacies digitais: potencialidades para a educação a distância. In: MACIEL, Cristiano et al. (org.). Educação a distância: experiências, vivências e realidades. Cuiabá: EdUFMT, 2016, p. 109-150.

SOUZA, Terezinha Fernandes Martins de; SILVA, Eli Lopes da; CRUZ, Dulce Márcia. Letramento digital: linguagens como processo de polifonia no ciberespaço. In: SIMPÓSIO HIPERTEXTO E TECNOLOGIAS NA EDUCAÇÃO, 5., 2013, Recife. Anais [...]. Recife: Universidade Federal de Pernambuco, 2013. http://nehte.com.br/simposio/anais/simposio2013.html. Acesso em: 19 abr. 2021.

STREET, Brian. Letramentos sociais: abordagens críticas do letramento no desenvolvimento, na etnografia e na educação. Tradução de Marcos Bagno. São Paulo: Parábola Editorial, 2014.

UNIVERSIDADE FEDERAL DE MATO GROSSO. Projeto do curso: licenciatura em pedagogia modalidade a distância. Cuiabá: EdUFMT, 2012. Disponível em: 
www.ufmt.br/ingressoead 2017/images/uploads/licenciatura/PPC-Pedagogia.pdf. Acesso em: 1 jun. 2021.

XAVIER, Antonio Carlos dos Santos. Letramento digital e ensino livro: conversas com linguistas:virtudes e controvérsias da linguística. 2. ed. São Pauo: Parábola Editorial, 2005 .

Recebido em: 02 julho 2021

Aceite em: 19 julho 2021 